\title{
CONDICIONAMENTO OSMÓTICO E GIBERELINA NA QUALIDADE FISIOLÓGICA DE SEMENTES DE PIMENTÃO COLHIDAS EM DIFERENTES ESTÁDIOS DE MATURAÇÃO ${ }^{1}$
}

\author{
KELINE SOUSA ALBUQUERQUE² ${ }^{2}$ RENATO MENDES GUIMARÃES ${ }^{3}$, LUIZ ANTONIO AUGUSTO GOMES ${ }^{3}$, \\ ANTONIO RODRIGUES VIEIRA ${ }^{4}$, MICHELLE FONSECA JÁCOME 5 .
}

\begin{abstract}
RESUMO - Considerando que o condicionamento osmótico e a aplicação do ácido giberélico são capazes de beneficiar a germinação e o vigor das sementes, objetivou-se com essa pesquisa verificar o efeito da associação do condicionamento osmótico com giberelina na qualidade das sementes de pimentão colhidas em diferentes estádios de maturação. Os frutos foram produzidos em ambiente protegido, utilizando-se os híbridos Magnata Super e Konan R, que foram colhidos em quatro estádios de maturação, com base na coloração dos frutos: completamente verdes (estádio 1), com 20 a 30\% de coloração avermelhada (estádio 2), com 40 a 50\% de coloração avermelhada (estádio 3 ) e completamente vermelhos (estádio 4). As sementes foram condicionadas em solução de $\mathrm{KNO}_{3}$ contendo giberelina nas seguintes concentrações: $0,50,100,200$ e 400 $\mu \mathrm{M}$. Foram feitas as seguintes determinações em laboratório: germinação, emergência, índice de velocidade de emergência, condutividade elétrica, análise das enzimas malato desidrogenase, álcool desidrogenase, catalase e proteínas resistentes ao calor. O condicionamento osmótico e o uso da giberelina não proporcionaram aumentos significativos na germinação de sementes de pimentão dos dois híbridos. Entretanto favoreceu a velocidade de emergência, principalmente em sementes colhidas nos estádios 3 e 4 . Verificou-se também efeito negativo do condicionamento osmótico em sementes colhidas no estádio 1 para ambos os híbridos. Concluiu-se que a associação dos tratamentos afeta positivamente o vigor das sementes de pimentão, com os melhores resultados verificados em sementes colhidas de frutos no início do amadurecimento, com 20 a 50\% de coloração avermelhada.
\end{abstract}

Termos para indexação: hortaliça, priming, regulador de crescimento.

\section{OSMOTIC CONDITIONING ASSOCIATED WITH GIBBERELLIC ACID ON PHYSIOLOGICAL QUALITY OF SWEET PEPPER SEEDS HARVEST IN DIFFERENT STAGE OF MATURATION}

\begin{abstract}
Considering that osmotic conditioning and gibberellic acid application can benefit germination and seed vigor, the objective of this study was to verify the effect of the association of osmotic conditioning with giberellic aid on the physiological quality of sweet pepper seeds at different maturation stages. The fruits were produced in a protected environment using the Magnata Super and Konan R hybrids, harvested at four maturation stages, based on the fruit coloration: completely green fruits (stage 1), fruits with 20 to $30 \%$ of red coloration (stage 2), fruits with 40 to $50 \%$ of red coloration
\end{abstract}

\footnotetext{
${ }^{1}$ Submetido em 20/04/2009. Aceito para publicação em 03/10/2009. Parte da Tese de Doutorado do primeiro autor, apresentada à UFLA, financiada pelo CNPq.
}

${ }^{2}$ Eng. Agr., Dr. Agronomia/Fitotecnia, UFLA, Cx P. 37, CEP: 37200-000, Lavras-MG, e-mail: kelinealbuquerque@yahoo.com.br.

${ }^{3}$ Eng. Agr. ,Dr., Prof. Adjunto, Dpto. de Agricultura, UFLA, Caixa Postal
P.37, CEP:37200-000, Lavras-MG, e-mail: renatomg@dag.ufla.br; laagomes@dag.ufla.br.

${ }^{4}$ Eng. Agr.,Dr., Pesquisador , EPAMIG/CTSM, Cx P.176, CEP.37200-000. Lavras-MG, e-mail: arvieira@epamig.ufla.br.

${ }^{5}$ Estudante de graduação do curso de Agronomia, UFLA, Lavras-MG, e-mail: michellejacome@bol.com.br. 
(stage 3) and completely red fruits (stage 4). The seeds were conditioned in $\mathrm{KNO}_{3}$ solution containing gibberellic acid at the following concentrations: 0, 50, 100, 200 and $400 \mu \mathrm{M}$. The parameters used to evaluate the treatments were: germination, emergence, speed emergence index, electrical conductivity tests and analyzes of the enzymes malate dehydrogenase, alcohol dehydrogenase, catalase and heat resistent protein. The osmotic conditioning and use of giberelic acid did not result in a meaningful increase in the germination of the sweet pepper seeds of the hybrids studied. However, it increased the emergence speed, principally in seeds harvest at stages 3 and 4. A negative effect of the osmotic conditioning in seeds harvested at stage 1 was also observed in both hybrids. The conclusion was that the association of the treatments affected positively the vigor of sweet pepper seeds and the best results were observed in seeds harvested from the fruits at the start of maturation, with 20 to $50 \%$ red coloration.

Index terms: vegetable, priming, plant growth regulator

\section{INTRODUÇÃO}

O pimentão é uma espécie conhecida por apresentar problemas no estabelecimento das plântulas, devido à baixa velocidade de germinação e emergência de plântulas, particularmente sob baixas temperaturas (Bradford et al., 1990), e, quando semeadas diretamente, a emergência é desuniforme e incompleta, prejudicando a implantação das lavouras.

Visando solucionar esse problema, diversos tratamentos pré-semeadura têm sido utilizados, dentre eles o condicionamento osmótico, que consiste na hidratação controlada das sementes em uma solução osmótica, estimulando o metabolismo das sementes sem, contudo, permitir a emissão da raiz primária (Bradford, 1986). Dessa forma, ativa-se a degradação de reservas, bem como sua translocação e assimilação, permitindo com que as sementes alcancem estado metabólico relativamente uniforme ao interromper o fornecimento de água. Várias pesquisas relatam efeitos positivos do condicionamento osmótico no aumento da velocidade de germinação e emergência, proporcionando maior uniformidade do estande, além de proporcionar germinação das sementes em condições adversas (Copeland e McDonald, 1995; Guimarães, 2000).

Com o intuito de favorecer o processo germinativo durante o condicionamento osmótico, algumas pesquisas têm utilizado giberelina associada a essa técnica. As giberelinas são substâncias que exercem papel chave na germinação de sementes, estando envolvidas tanto na superação da dormência como no controle da hidrólise de reservas (Taiz e Zeiger, 2004). Em pimentão, o efeito positivo da giberelina em sementes tem sido relatado por reduzir a resistência imposta pelo endosperma, favorecendo a germinação (Watkins e Cantliffe, 1983). A giberelina associada com matricondicionamento também promoveu aumento significativo da emergência de sementes de tomate e mamão (Andreoli e Khan, 1993 e 1999; Lopes e Souza, 2008).

Considerando que o condicionamento osmótico e a aplicação do ácido giberélico são capazes de beneficiar a germinação e o vigor das sementes, objetivou-se com essa pesquisa verificar o efeito da associação dos referidos tratamentos na qualidade fisiológica das sementes de pimentão em diferentes estádios de maturação.

\section{MATERIAL E MÉTODOS}

A produção das sementes foi realizada em parceria com a empresa Hortiagro ${ }^{\circledR}$, localizada em Ijaci, município da região sul de Minas Gerais, com temperaturas médias variando de 18 a $25{ }^{\circ} \mathrm{C}$. As análises da qualidade das sementes foram conduzidas no Laboratório Central de Sementes do Departamento de Agricultura da Universidade Federal de Lavras, em Lavras-MG.

Foram utilizadas sementes dos híbridos Magnata Super e Konan R. A semeadura foi realizada em viveiro, utilizando-se bandejas de isopor. Após a semeadura e obtenção das mudas, foi realizado o transplantio em linha para local definitivo, em ambiente protegido com sistema de fertirrigação. A colheita dos frutos foi realizada durante os meses de julho e agosto de 2007, sendo colhidos em quatro estádios de maturação: completamente verdes (estádio 1), com 20 a $30 \%$ de coloração avermelhada 
(estádio 2), com 40 a $50 \%$ de coloração avermelhada (estádio 3) e completamente vermelhos (estádio 4). Após a colheita, as sementes foram extraídas manualmente, submetidas à secagem artificial com temperatura de $35{ }^{\circ} \mathrm{C}$ e acondicionadas para posterior realização do condicionamento.

O condicionamento osmótico foi realizado em solução aerada de $\mathrm{KNO}_{3}$ num potencial osmótico de $-1,1 \mathrm{MPa}$, a $25^{\circ} \mathrm{C}$, na ausência de luz, por seis dias. A concentração do sal foi baseada na equação de Van't Hoff (Hillel, 1971). Na solução osmótica foi adicionada giberelina nas concentrações de $0,50,100,200$ e $400 \mu \mathrm{M}$. Após o período de condicionamento osmótico, as sementes foram secadas em temperatura ambiente, em torno de $25^{\circ} \mathrm{C}$, por 24 horas, para então serem realizadas as seguintes avaliações: Teor de água - determinado pelo método da estufa a $105 \pm 3$ ${ }^{\circ} \mathrm{C}$, por 24 horas, utilizando-se duas repetições de $4,0 \mathrm{~g}$ de sementes por tratamento. Os resultados foram expressos em porcentagem (Brasil, 1992). Teste de germinação - foi conduzido em câmara de germinação, tipo BOD, regulada à temperatura alternada $20-30{ }^{\circ} \mathrm{C}$, com fotoperíodo de oito horas. As sementes foram semeadas superficialmente em substrato areia lavada, autoclavada e umedecida com água destilada com $70 \%$ da capacidade de campo, em caixas plásticas para germinação $(11 \times 11 \times 3,5 \mathrm{~cm})$. Foram utilizadas quatro repetições de 50 sementes por tratamento. As contagens das plântulas normais foram realizadas no sétimo e $14^{\circ}$ dia após a semeadura (Brasil, 1992). Foram consideradas plântulas normais aquelas com raiz primária e parte aérea desenvolvidas. Teste de emergência de plântulas - foi realizado em bandejas plásticas contendo como substrato solo + areia, na proporção 1:2 e umedecido com água destilada com $70 \%$ da capacidade de campo. Foram utilizadas quatro repetições de 50 sementes por tratamento. Após a semeadura, realizada superficialmente, as bandejas foram mantidas em câmara de crescimento vegetal, à temperatura de $25{ }^{\circ} \mathrm{C}$. Foi considerada a porcentagem de plântulas emersas aos 14 dias. Índice de velocidade de emergência (IVE) - foi avaliado conjuntamente com a emergência, a partir da contagem diária do número de plântulas emersas, de acordo com Maguire (1962). Condutividade elétrica - foram usadas quatro repetições de 50 sementes, pesadas e colocadas em copos plásticos contendo $50 \mathrm{~mL}$ de água destilada, permanecendo em embebição por 24 horas em câmara de germinação, tipo BOD, a $25{ }^{\circ} \mathrm{C}$ (Oliveira e Novembre, 2005). As leituras foram realizadas com condutivimetro Digimed, modelo CD-21, com resultados expressos em $\mu \mathrm{S} \mathrm{cm}^{-1} \mathrm{~g}^{-1}$. Análise de isoenzimas - as sementes de cada tratamento foram maceradas em cadinho contendo PVP (antioxidante) e nitrogênio líquido. Para cada isoenzima analisada, retiraram-se $100 \mathrm{mg}$ do material macerado nos quais foram aplicados $500 \mu \mathrm{L}$ do tampão (Tris- $\mathrm{HCl} 0,2 \mathrm{M} \mathrm{pH} \mathrm{8,0)} \mathrm{e} 0,1 \%$ de $\beta$-mercaptanol. Logo depois, os microtubos foram agitados e mantidos a $4{ }^{\circ} \mathrm{C}$ durante 12 horas. Em seguida, as amostras foram centrifugadas a $16.000 \mathrm{xg}$ por 30 minutos a $4{ }^{\circ} \mathrm{C}$, sendo retirados $80 \mu \mathrm{L}$ do sobrenadante os quais foram aplicados no gel de poliacrilamida 7,5\% (gel separador) e 4,5\% (gel concentrador). A corrida eletroforética foi realizada por cinco horas, a $120 \mathrm{~V}$. Após a corrida, os géis foram revelados para os sistemas álcool desidrogenase (ADH), malato desidrogenase (MDH) e catalase (CAT), seguindo o protocolo descrito por Alfenas et al. (1991). Extração de proteínas resistentes ao calor - foram utilizados $100 \mathrm{mg}$ do material macerado, aos quais se adicionaram $1.800 \mu \mathrm{L}$ de tampão de extração $(50 \mathrm{mM}$ Tris- $\mathrm{HCl} \mathrm{pH} 7,5$; $0,5 \mathrm{M} \mathrm{NaCl}, 0,005 \mathrm{M} \mathrm{MgCL}_{2}, 0,001 \mathrm{M}$ PMSF) e agitados. Em seguida, o material foi centrifugado a $14.000 \mathrm{xg}$ por 20 minutos a $4{ }^{\circ} \mathrm{C}$, o sobrenadante incubado em banhomaria a $80{ }^{\circ} \mathrm{C}$ por 10 minutos e novamente centrifugado. Em $100 \mu \mathrm{L}$ do sobrenadante foram adicionados $50 \mu \mathrm{L}$ de solução tampão da amostra $(2,5 \mathrm{~mL}$ de glicerol, $0,46 \mathrm{~g}$ de SDS e $20 \mathrm{mg}$ de azul bromofenol) e colocados em banho-maria com água fervente por cinco minutos. A corrida eletroforética foi realizada por oito horas a $120 \mathrm{~V}$. Após a corrida, os géis foram corados usando o produto coomassie blue a $0,05 \%$, durante 15 horas e descolorados em solução de ácido acético $10 \%$, de acordo com Alfenas et al. (1991). Análise estatística - utilizou-se o esquema fatorial $2 \times 4 \times 5$ (dois híbridos, quatro estádios de maturação e cinco concentrações de giberelina), em delineamento inteiramente casualizado, com quatro repetições. Para as variáveis germinação, emergência, condutividade elétrica e IVE foram realizados estudos de regressão.

\section{RESULTADOS E DISCUSSÃO}

Analisando os teores de água após o condicionamento osmótico, foi observado, para o híbrido Magnata Super, maiores valores em sementes colhidas no estádio 1, variando de 62 a 64\%. Para o híbrido Konan R, a variação entre os estádios de maturação foi muito baixa, variando de 54 a $56 \%$ em todos os estádios. Os altos teores de água observados podem ter ocorrido pela utilização do $\mathrm{KNO}_{3}$ como agente osmótico, que, pelas propriedades físicas, 
possivelmente pode ter sido absorvido pelas sementes, reduzindo o potencial interno das mesmas e favorecendo a absorção de água, como constatado por Roveri-José et al. (2000) em sementes de pimentão osmocondicionadas com $\mathrm{KNO}_{3}$

Avaliando a germinação (Figura 1), verificou-se para o híbrido Magnata Super que os maiores valores foram obtidos em sementes colhidas no estádio 4 , com tendência de aumento à medida que se aumentaram as doses de giberelina. O mesmo comportamento foi observado para sementes no estádio 3, entretanto, para sementes colhidas no estádio 2, concentrações de giberelina a partir de 200 $\mu \mathrm{M}$ provocaram redução da germinação. No híbrido Konan verificou-se que a presença de giberelina no condicionamento promoveu aumentos na germinação apenas nos estádio 2 e 3 com doses de até $200 \mu \mathrm{M}$. O efeito da combinação de condicionamento e giberelina também foi avaliado por Andreoli e Khan (1999), que obtiveram mais de $80 \%$ de sementes de pimentão germinadas com doses de giberelina entre 100 e $400 \mu \mathrm{M}$. Em sementes de mamão, a combinação de giberelina e condicionamento osmótico, além de propiciar aumento na germinação, ainda promoveu maior uniformidade (Aroucha et al., 2006). O favorecimento da germinação ocasionada pelo condicionamento osmótico deve-se ao acúmulo de solutos provenientes do início do metabolismo da semente, promovendo a emergência da radícula e a formação da plântula em menor espaço de tempo. A ação da giberelina também interfere nos processos metabólicos, induzindo o crescimento do hipocótilo (Santos e Menezes, 2000; Taiz e Zeiger, 2004).
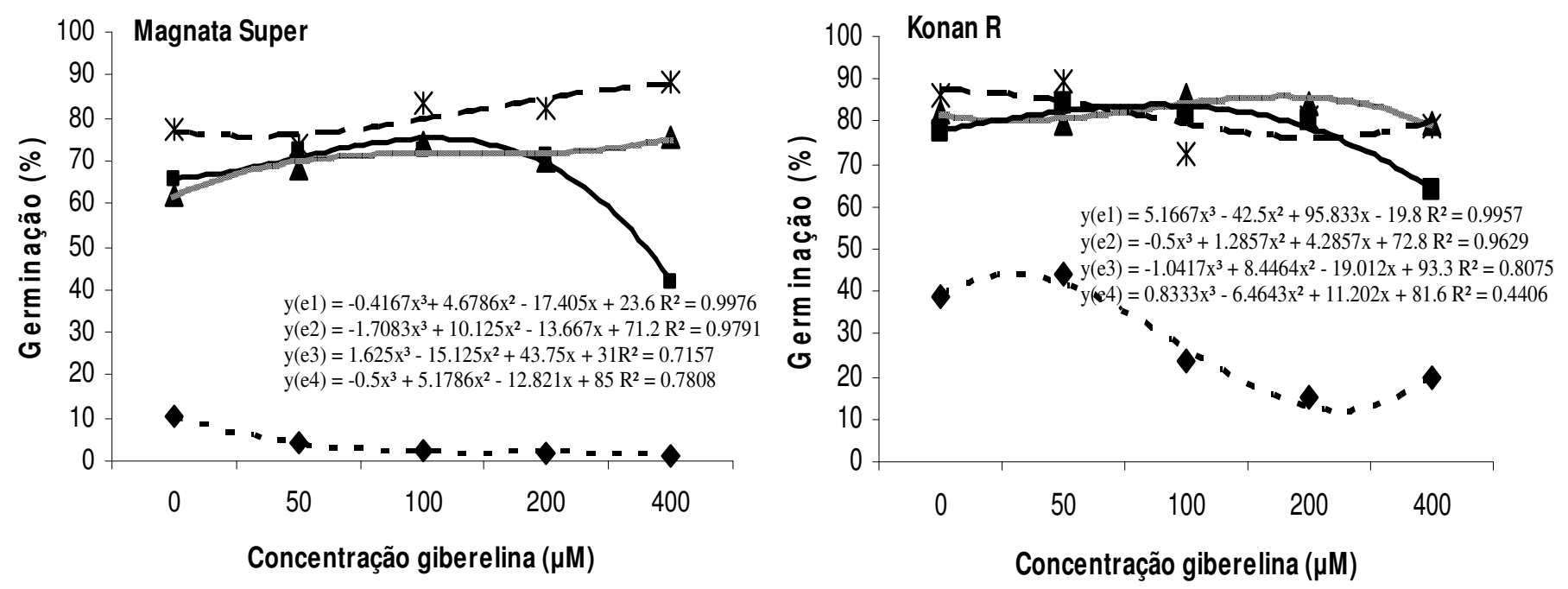

? estádio 1 ? estádio 2 ? estádio 3 * estádio 4

FIGURA 1. Germinação (\%) de sementes de pimentão, híbridos Magnata Super e Konan R, em função do estádio de maturação e do condicionamento osmótico associado com giberelina.

Entretanto, neste estudo, a giberelina associada ao condicionamento fisiológico não proporcionou ganhos expressivos, principalmente para sementes colhidas nos estádios 3 e 4 . Isso possivelmente pode ter ocorrido devido ao fato de que as sementes, por serem híbridas, bem como recém colhidas, já se apresentavam altamente vigorosas ao serem submetidas ao tratamento. Sementes de alface com alta viabilidade, ao serem submetidas ao condicionamento osmótico, não apresentaram qualquer benefício (Fessel et al., 2001). Em sementes de café também foi constatada a ineficiência do condicionamento osmótico para melhorar o desempenho germinativo de sementes com alto vigor (Pertel et al, 2001).

Pelo teste de condutividade elétrica (Figura 2), observou-se para o híbrido Magnata Super que os menores valores foram obtidos em sementes colhidas no estádio 4 . Para sementes colhidas nos estádios 2 e 3 ocorreu tendência de aumento da condutividade com a aplicação de giberelina, principalmente na utilização de $400 \mu \mathrm{M}$. No híbrido Konan $\mathrm{R}$ os menores valores de condutividade foram verificados para sementes colhidas nos estádios 3 e 4, com tendência de redução com o uso da giberelina. 


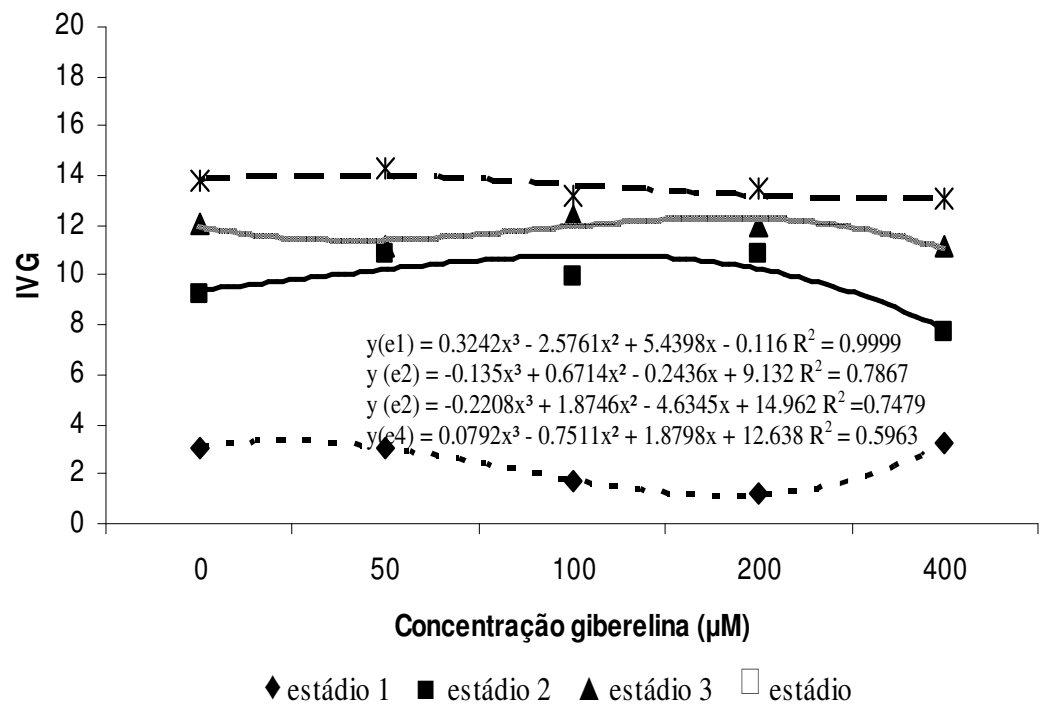

FIGURA 2. Condutividade elétrica $\left(\mu \mathrm{S} \mathrm{cm} \mathrm{cm}^{-1} \mathrm{~g}^{-1}\right)$ de sementes de pimentão, híbridos Magnata Super e Konan R, em função do estádio de maturação e do condicionamento osmótico associado com giberelina.

É comum observar altos valores de condutividade em condicionamento osmótico com soluções salinas, pois os íons dissociados dessas soluções podem penetrar nos tecidos das sementes e, posteriormente serem liberados na solução de embebição, contribuindo para alterar os resultados. Em estudos realizados com sementes de pimentão foram relatados altos valores de condutividade elétrica em tratamentos utilizando soluções salinas (Roveri-José et al., 2000). Entretanto, o alto valor de condutividade observado para sementes colhidas no estádio 1 sugere desestruturação do sistema de membranas, provavelmente por causa da imaturidade das mesmas, fato este reforçado também pelos resultados dos outros testes fisiológicos.

Pela análise da emergência (Figura 3), verificou-se que o condicionamento das sementes de pimentão foi benéfico para aquelas do híbrido Magnata Super colhidas a partir do estádio 2, alcançando valores máximos para sementes colhidas no estádio 4 , independente da presença de giberelina no condicionamento, registrando valores acima de $90 \% \mathrm{em}$ todas as doses utilizadas. Em sementes do híbrido Konan $\mathrm{R}$, o aumento da emergência foi proporcional ao avanço do processo de maturação até o estádio 3 , verificando-se queda da emergência em sementes colhidas no estádio 4 . Observou-se baixo desempenho em sementes colhidas no estádio 1. Comportamento semelhante à emergência foi observado também para o IVE (Figura 4), com aumento da velocidade a partir do avanço da maturação para sementes osmocondicionadas sem giberelina em ambos os híbridos. Observou-se tendência de aumento da velocidade com aplicação da giberelina para sementes colhidas nos estádios 2 e 3. A combinação de matricondicionamento e giberelina resultou em maior velocidade de emergência de plântulas de tomate e pimentão (Andreoli e Khan,1999), sugerindo que o efeito benéfico desse fitohormônio está relacionado não somente com a redução da restrição mecânica, mas também com fornecimento de energia para o crescimento do embrião.

Pela análise do perfil enzimático da malato desidrogenase (MDH), verificou-se para o híbrido Magnata Super (Figura 5a), alta atividade dessa enzima para sementes colhidas no estádio 1. A partir do estádio 3 ocorreu diminuição da sua atividade, sem alteração com o avanço da maturação. A alta atividade observada no estádio 1 pode ser devido à alta taxa de respiração em consequência de algum dano ocorrido, pois nesse estádio as sementes encontravam-se imaturas e provavelmente suas membranas desestruturadas. Para o híbrido Konan R (Figura 5b) foi observada alteração da atividade enzimática ao longo dos estádios de maturação, com diminuição da sua atividade em sementes no estádio 4 submetidas às concentrações de 200 e $400 \mu \mathrm{M}$ de giberelina. Em estudo com sementes de soja, foi verificada, durante o desenvolvimento, alta atividade da enzima em estádios precoces, com posterior redução e tornando-se constante ao longo do desenvolvimento (Silva 2006). A MDH é uma 
enzima diretamente relacionada com a respiração aeróbica, exercendo importante função no ciclo de Krebs, catalisando a reação de malato em oxalacetato para produção de NADH.
A redução da sua atividade está associada à desestruturação das membranas das mitocôndrias, diminuindo a produção de ATP e a absorção de oxigênio (Bray et al., 2000).
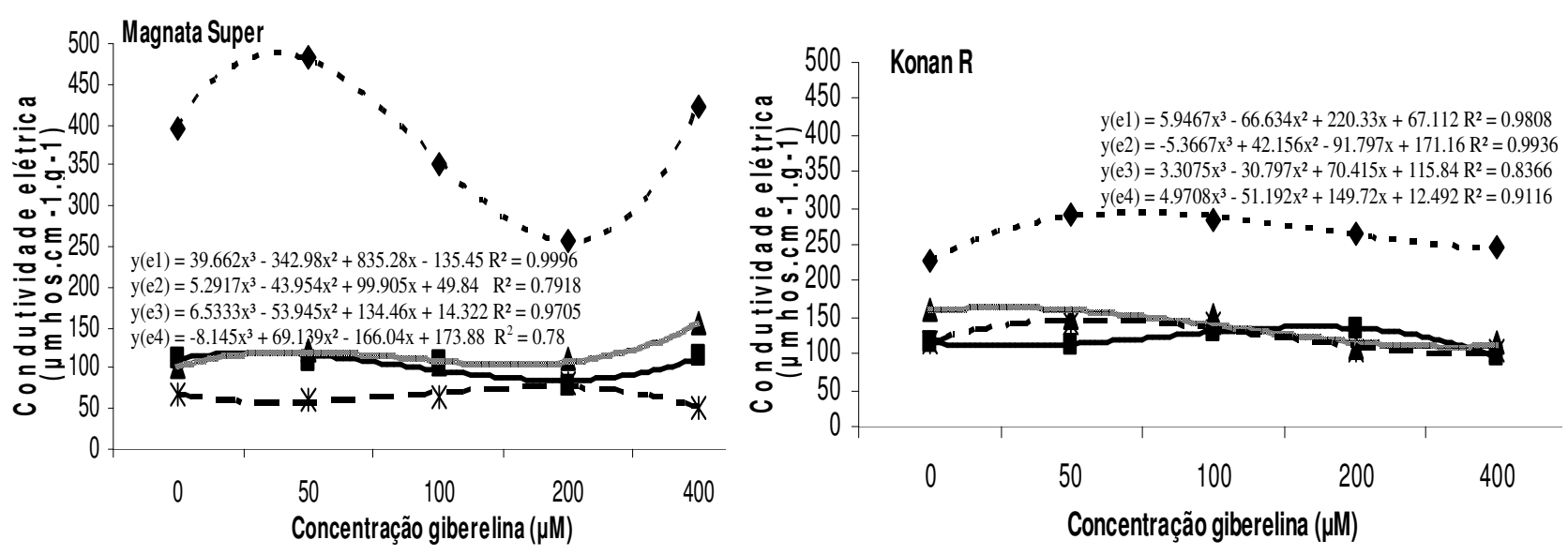

- estádio 1 - estádio $2 \boldsymbol{\Delta}$ estádio 3 * estádio 4

FIGURA 3. Emergência (\%) de plântulas de pimentão, híbridos Magnata Super e Konan R, em função do estádio de maturação e do condicionamento osmótico associado com giberelina.
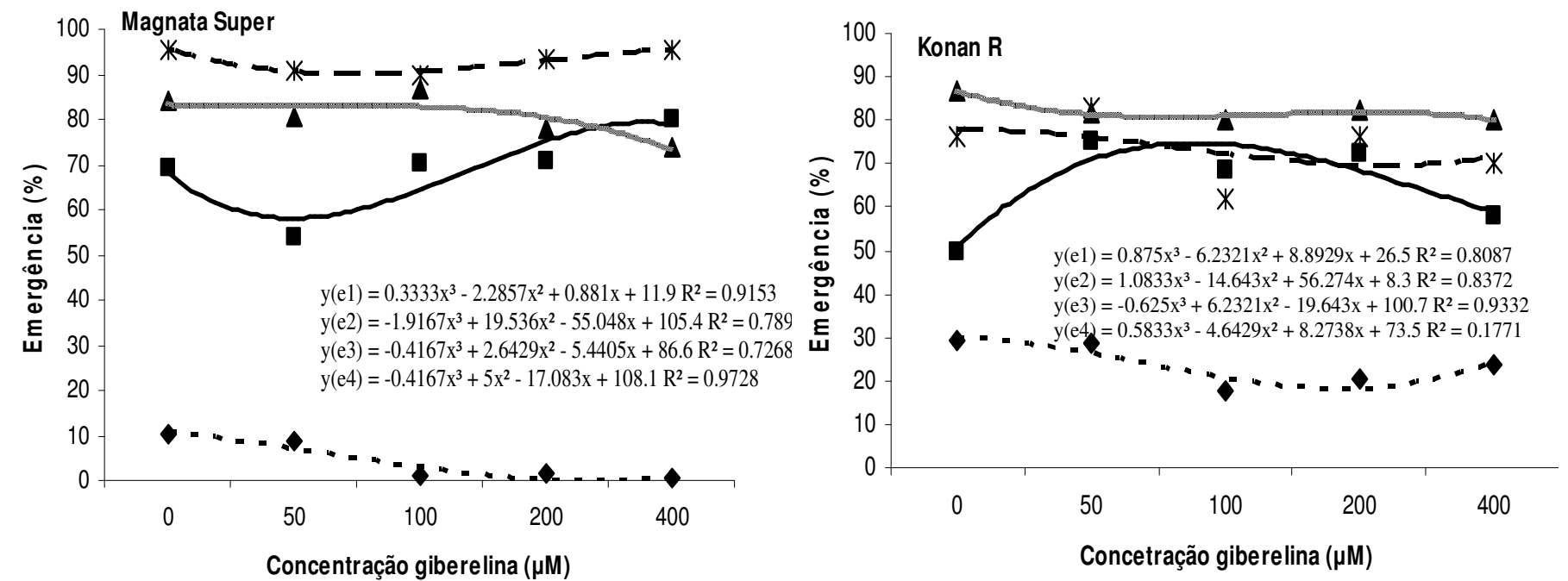

? estádio 1 ? estádio 2 ? estádio 3 * estádio 4

FIGURA 4. Índice de velocidade de emergência (IVE) de plântulas de pimentão, híbridos Magnata Super e Konan R, em função do estádio de maturação e do condicionamento osmótico associado com giberelina. 

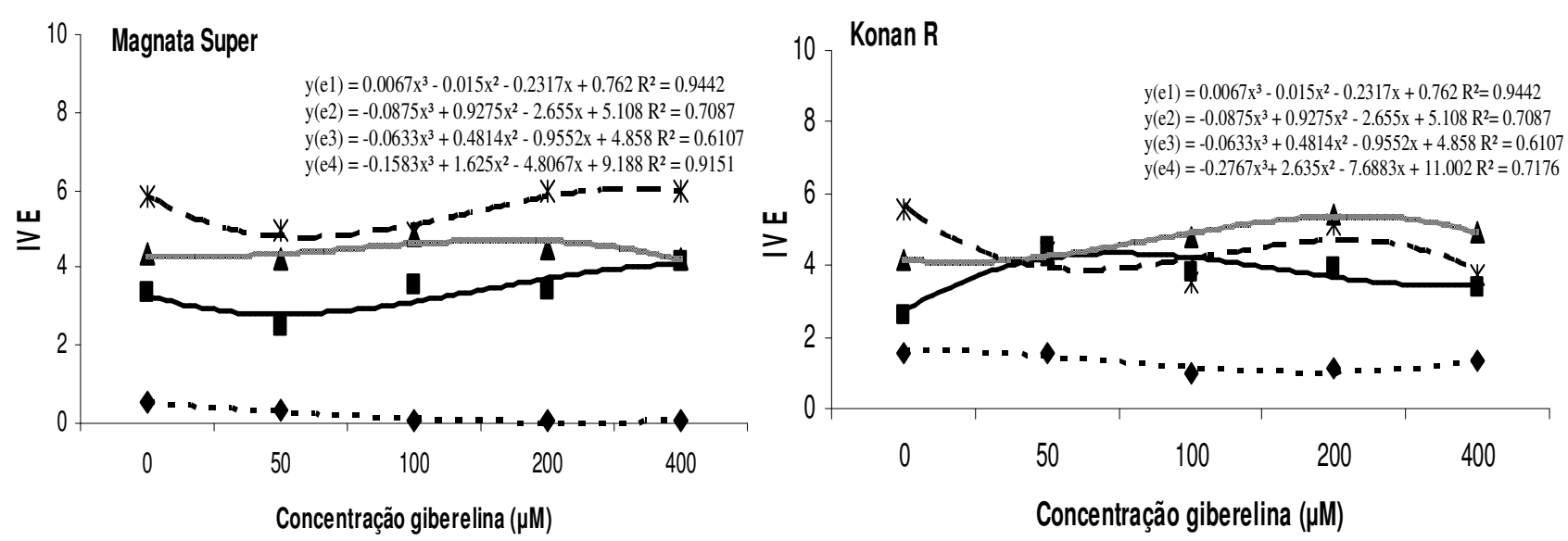

? estádio 1 ? estádio 2 ? estádio 3 * estádio 4

FIGURA 5. Perfil enzimático da malato desidrogenase (MDH) em sementes de pimentão, híbridos Magnata Super (a) e Konan R (b), em função do estádio de maturação e do condicionamento osmótico associado com

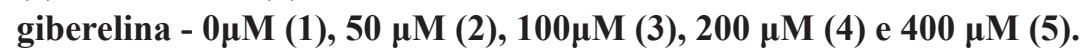

Pelos padrões isoenzimáticos da álcool desidrogenase (ADH), verificou-se para o híbrido Magnata Super (Figura 6a) atividade da enzima em sementes colhidas nos estádios 1 e 2, independente da concentração de giberelina. Entretanto, no estádio 3 houve atividade apenas nas sementes condicionadas sem giberelina. No estádio 4 constatou-se alta atividade em todos os tratamentos. Com relação ao híbrido Konan R (Figura 6b), observou-se no estádio 1 alta atividade para sementes submetidas ao condicionamento sem giberelina; com aumento da concentração houve redução dessa atividade. Para sementes colhidas nos estádios 2 e 3 foi observada alta atividade enzimática independente da dose de giberelina. No estádio 4 a atividade da enzima foi reduzindo à medida que se aumentou a concentração de giberelina. A ADH atua no metabolismo anaeróbico, reduzindo acetaldeído a etanol e oxidando NADH a NAD ${ }^{+}$ (Bray et al., 2000). É provável que a atividade da ADH revelada para os tratamentos esteja associada com acúmulo de acetaldeído. Essa atividade pode ainda resultar em um suprimento adequado de ATP, via fermentação alcoólica. Entretanto, Taiz e Zeiger (2004) afirmam que, mais importante que o fornecimento energético exercido pela $\mathrm{ADH}$, é a sua capacidade de converter o acetaldeído tóxico em etanol.
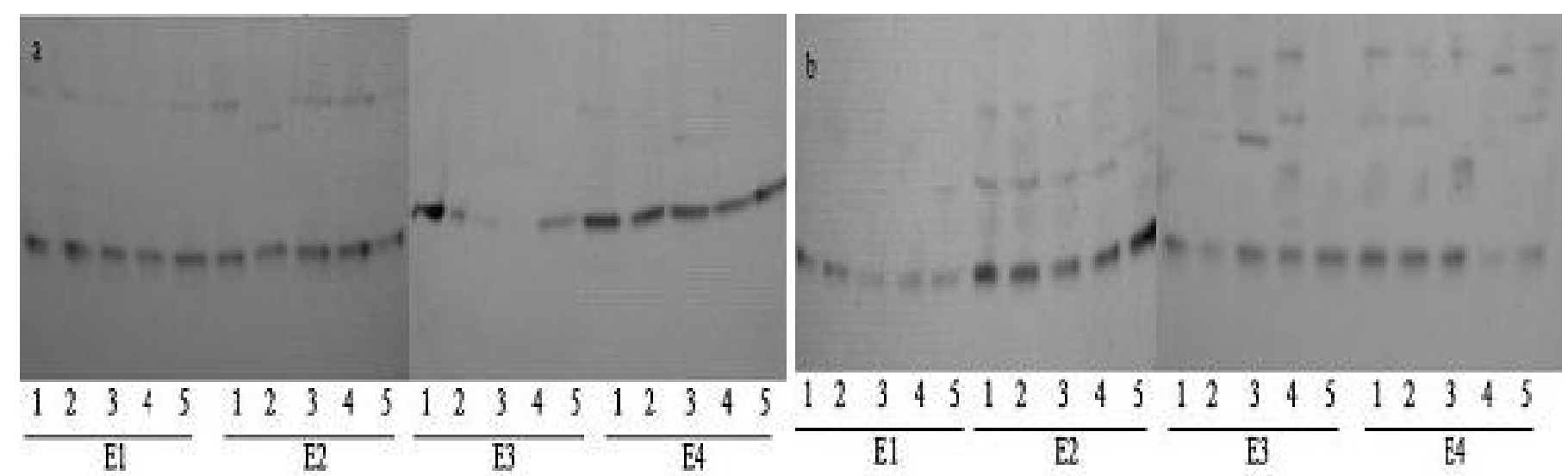

FIGURA 6. Padrão eletroforético da enzima álcool desidrogenase (ADH) em sementes de pimentão, híbridos Magnata Super (a) e Konan R (b), em função do estádio de maturação e do condicionamento osmótico associado

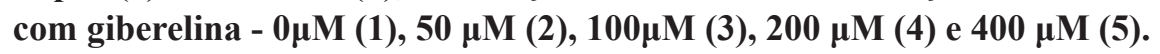


Em relação ao perfil enzimático da catalase, foi observada, para sementes do híbrido Magnata Super (Figura 7a), uma baixa atividade enzimática no estádio 1, com aumento da sua atividade no estádio 2; entretanto, a partir do estádio 3 foi observada diminuição da sua atividade. As sementes do Konan R (Figura 7b) apresentaram comportamento semelhante ao do híbrido Magnata Super, entretanto verificou-se alta atividade nos estádios 3 e 4 . A catalase é uma enzima antioxidante do sistema de defesa, envolvida na remoção de peróxido de hidrogênio. A redução da atividade dessa enzima faz com que as sementes fiquem mais suscetíveis aos efeitos deletérios de radicais livres sobre os ácidos graxos insaturados das membranas, comprometendo o seu vigor. Em sementes de girassol envelhecidas artificialmente também foi observada menor atividade da catalase (Bailly et al., 1996). A baixa atividade observada no estádio 1, para ambos os híbridos,pode ter ocorrido possivelmente por as sementes estarem imaturas e, consequentemente, ainda não apresentarem eficiência de mecanismos removedores de radicais livres. Resultados semelhantes foram relatados no desenvolvimento de sementes de soja (Silva, 2006).
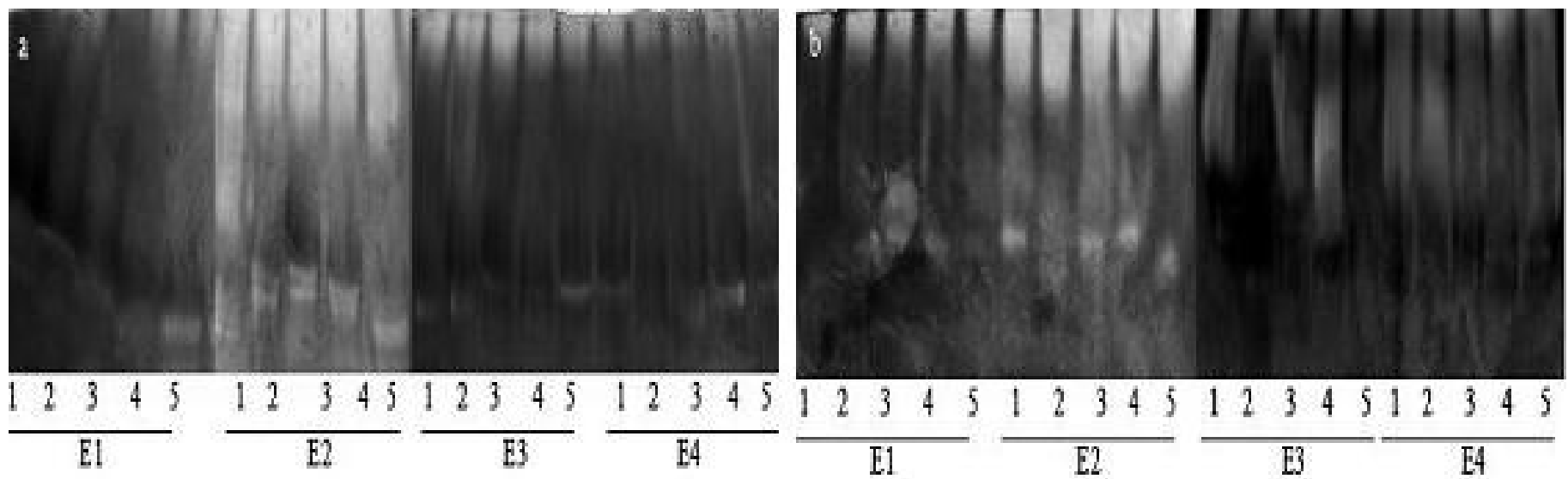

FIGURA 7. Perfil enzimático da catalase (CAT) em sementes de pimentão, híbridos Magnata Super (a) e Konan R (b), em função do estádio de maturação e do condicionamento osmótico associado com giberelina - $0 \mu \mathrm{M}$ (1), $50 \mu \mathrm{M}(2), 100 \mu \mathrm{M}$ (3), $200 \mu \mathrm{M}$ (4) е $400 \mu \mathrm{M}$ (5).

O perfil eletroforético de proteínas tolerantes ao calor mostra a presença dessas proteínas em todos os estádios de maturação, para ambos os híbridos, independente da utilização de giberelina. Para sementes do híbrido Magnata Super (Figura 8a), verificou-se aumento do número de bandas à medida que se avança a maturação. Nota-se o surgimento de um maior número de bandas à partir do estádio 2 , tornando-se mais evidentes no estádio 3. Esses resultados estão de acordo com os observados por Faria et al. (2004) em sementes de milho colhidas em diferentes estádios de linha de leite.
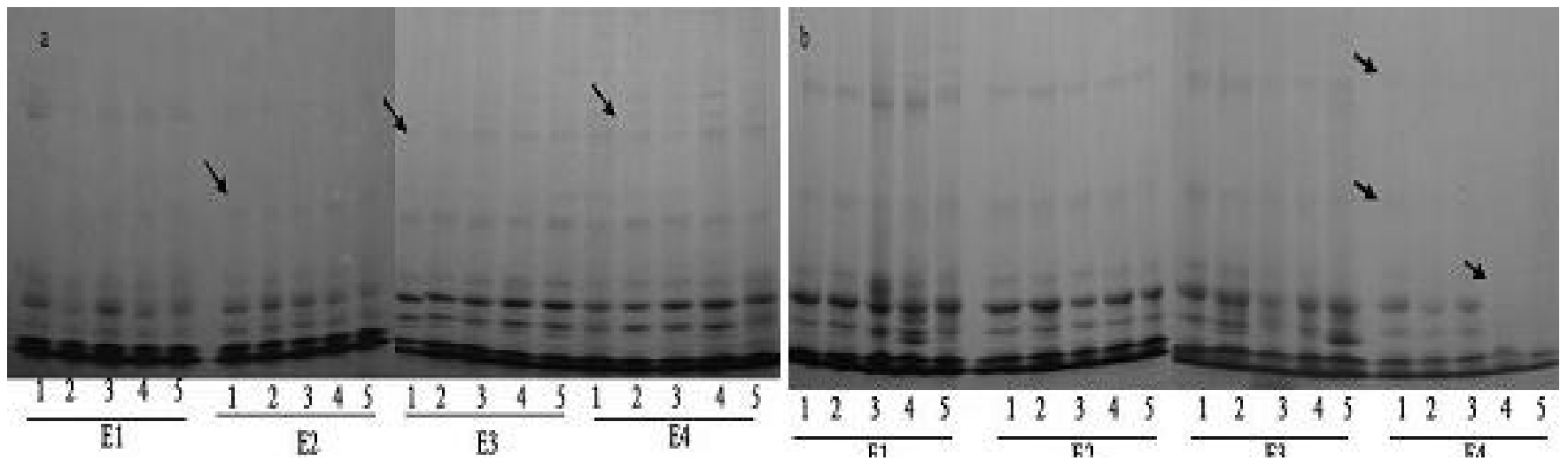

FIGURA 8. Perfil eletroforético de proteínas resistentes ao calor em sementes de pimentão, híbridos Magnata Super (a) e Konan $\mathrm{R}$ (b), em função do estádio de maturação e do condicionamento osmótico associado com

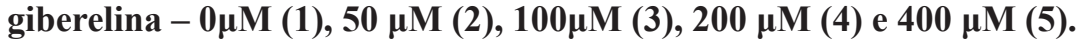


Proteínas tolerantes ao calor são acumuladas durante os estádios finais da maturação, no momento em que a semente começa a perder água, e que suas propriedades físicas de estabilidade e hidrofilicidade e sua abundância lhe sugerem um importante papel na tolerância a dessecação (Black et al.,1999). O acúmulo de banda nos estádios precoces foi verificado para sementes do Konan R (Figura 8b); entretanto, no estádio mais avançado ocorreu redução do número de bandas, com ausência destas de forma evidente em sementes condicionadas com 200 e $400 \mu \mathrm{M}$ de giberelina. Esses resultados coincidem com as avaliações fisiológicas, tais como condutividade elétrica que, segundo Guimarães (2000), indicam que a presença dessas proteínas está associada à proteção dos sistemas de membranas.

\section{CONCLUSÕES}

$\mathrm{O}$ condicionamento osmótico com $\mathrm{KNO}_{3}$ e a aplicação de giberelina não proporciona aumentos significativos do desempenho germinativo em sementes de pimentão dos híbridos: Magnata Super e Konan R. O condicionamento, favorece a velocidade de emergência, principalmente em sementes colhidas de frutos no início do amadurecimento, com 20 a $50 \%$ de coloração avermelhada.

\section{REFERÊNCIAS}

ALFENAS, A.C.; PETERS, I.; BRUNE, W.; PASSADOR, G.C. Eletroforese de proteínas e isoenzimas de fungos e essências florestais. Viçosa: UFV, 1991. 242p.

ANDREOLI, C.; KHAN, A.A. Improving seedling emergence of papaya, Carica papaya L., by combining matriconditioning and gibberellin treatment. HortScience, v.28, n.7, p.708-709, 1993.

ANDREOLI, C.; KHAN, A.A. Matriconditioning integrated with gibberellic acid to hasten seed germination and improve stand establishment of pepper and tomato. Pesquisa Agropecuária Brasileira, v.34, n.10, p.1953-1958, 1999.

AROUCHA, E.M.M.; SILVA, R.F.; NUNES, G.H.S.; SANTOS, M.C.M.A. Condicionamento osmótico na germinação de sementes de mamão (Carica papaya L.). Revista Caatinga, v.19, n.3, p.272-277, 2006.

BAILly, C.; BENAMAR, A.; COBINEAU, F.; CÔME, D. Changes in malondialdehyde content and superoxide dismutase, catalase, and glutathione reductase activities in sunflower seeds as related to deterioration during accelerated aging. Physiologia Plantarum, v.97, n.1, p.104-110, 1996.

BLACK, M.; CORBINEAU, F.; GEE, H.; CÔME, D.
Water content, raffinose, and dehydrins in the induction of desiccation tolerance in immature wheat embryos. Plant Physiology, v.120, n.22, p. 463-471, 1999.

BRADFORD, K.J. Manipulation of seed water relations via osmotic priming to improve germination under stress conditions. HortScience, v.21, n.5, p.1105-1112, 1986.

BRADFORD, K.J.; STEINER, J.J.; TRAWATHA, S.E. Seed priming influence on germination and emergence of pepper seed lots. Crop Science, v.30, n.3, p.718-721, 1990.

BRASIL. Ministério da Agricultura e Reforma Agrária. Secretaria Nacional de Defesa Agropecuária. Departamento Nacional de Produção Vegetal. Coordenação de Laboratório Vegetal. Regras para Análise de Sementes. Brasília, DF, 1992. 365p.

BRAY, E.A.; BAILEY-SERRES, J.; WERETILNYK, E. Responses to abiotic stresses. In: BUCHANAN, B.B.; GRUISSEM, W.; JONES, R.L. (Ed.). Biochemistry and molecular biology of plants. Rockville: American Society of Plant Physiologists, 2000. cap.22, p.1158-1203.

COPELAND, L.O.; McDONALD, M.B. Seed science and technology. 3.ed. New York: Chapman e Hall, 1995. 409p.

FARIA, M.A.V.R.; VON PINHO, R.G.; VON PINHO, E.V.R.; GUIMARÃES, R.M.; FREITAS, F.E.O. Germinabilidade e tolerância à dessecação em sementes de milho colhidas em diferentes estádios de maturação. Revista Brasileira de Milho e Sorgo, v.3, n.2, p.276-289, 2004.

FESSEL, S.A.; VIEIRA, R.D.; RODRIGUES, T.J.D.; FAGIOLI, M.; PAULA, R.C. Eficiência do condicionamento osmótico em sementes de alface. Revista Brasileira de Sementes, v.23, n.1, p. 128-133, 2001.

GUIMARÃES, R.M. Tolerância à dessecação e condicionamento fisiológico em sementes de cafeeiro (Coffea arabica, L.). 2000, 180f. Tese (Doutorado em Fitotecnia) - Universidade Federal de Lavras, Lavras.

HILLEL, D. Soil and water: physical principles and processes. New York: Academic Press, 1971. 288p.

LOPES, H.M.; SOUZA, C.M. Efeitos da giberelina e da secagem no condicionamento osmótico sobre a viabilidade e o vigor de sementes de mamão (Carica papaya L.). Revista Brasileira de Sementes, v.30, n.1, p.181-189, 2008.

MAGUIRE, J.D. Speed of germination aid in selection and evaluation for seedling and vigour. Crop Science, v.2, n.2, p.176-177, 1962.

OLIVEIRA, S.R.S; NOVEMBRE, A.D.L.C. Teste de condutividade elétrica para as sementes de pimentão. Revista Brasileira de Sementes, v.27, n.1, p.31-36, 2005. 
PERTEL, J.; DIAS, D.C.F.S.; DIAS, L.A.S.; ALVARENGA, E.M. Efeito do condicionamento fisiológico na germinação e no vigor de sementes de café (Coffea arabica L.). Revista Brasileira de Armazenamento, Especial, n.3, p.39-45, 2001.

ROVERI-JOSÉ, S.C.B.; VIEIRA, M.G.G.C.; GUIMARÃES, R.M. Efeito da temperatura e do período de condicionamento osmótico na germinação e no vigor de sementes de pimentão. Revista Brasileira de Sementes, v.22, n.2, p.176-184, 2000.

SANTOS, C.M.R.; MENEZES, N.L. Tratamentos pré- germinativos em sementes de alface. Revista Brasileira de Sementes, v.22, n.1, p.153-158, 2000.

SILVA, P.A. Estudo da qualidade fisiológica, bioquímica e ultra-estrutural durante o desenvolvimento e a secagem de sementes de soja. 2006. 55f. Tese (Doutorado em Fitotecnia) - Universidade Federal de Lavras, Lavras, 2006.

TAIZ, L.; ZEIGER, E. Fisiologia vegetal. 3 ed. Porto Alegre: Artmed, 2004. 719p.

WATKINS, J.T.; CANTLIFFE, J.D. Hormonal control of pepper seed germination. HortScience, v.18, n.3, p.342-343, 1983. 